\title{
Selection for Quantitative Trait Loci Associated with Resistance to Stewart's Wilt in Sweet Corn
}

\author{
J. K. Pataky, M. O. Bohn, J. D. Lutz, and P. M. Richter
}

First and second authors: University of Illinois, Department of Crop Sciences, Urbana 61801; and third and fourth authors: General Mills Agriculture Research, Le Sueur, MN 56058.

Accepted for publication 22 December 2007.

\section{ABSTRACT}

Pataky, J. K., Bohn, M. O., Lutz, J. D., and Richter, P. M. 2008. Selection for quantitative trait loci associated with resistance to Stewart's wilt in sweet corn. Phytopathology 98:469-474.

The objectives of this research were to identify quantitative trait loci (QTL) for Stewart's wilt resistance from a mapping population derived from a sweet corn hybrid that is highly resistant to Pantoea stewartii and to determine if marker-based selection for those QTL could substantially improve Stewart's wilt resistance in a population derived from a cross of resistant lines and a highly susceptible sweet corn inbred. Three significant QTL for Stewart's wilt resistance on chromosomes 2 (bin 2.03), 5 (bin 5.03), and 6 (bin 6.06/6.07) explained $31 \%$ of the genetic variance in a population of $110 \mathrm{~F}_{3: 4}$ families derived from the sweet corn hybrid Bonus. The three QTL appeared to be additive in their effects on Stewart's wilt ratings. Based on means of families that were either homozygous or heterozygous for marker alleles associated with the resistance QTL, the QTL on chromosomes 2 and 6 appeared to have dominant or partially dominant gene action, while the QTL on chromosome 5 appeared to be recessive. A population of $422 \mathrm{BC}_{2} \mathrm{~S}_{2}$ families was derived from crosses of a sweet corn inbred highly susceptible to Stewart's wilt, Green Giant Code 88 (GG88), and plants from two $\mathrm{F}_{3: 4}$ families (12465 and 12467) from the Bonus mapping population that were homozygous for marker alleles associated with Stewart's wilt resistance at the three QTL. Mean Stewart's wilt ratings for $\mathrm{BC}_{2} \mathrm{~S}_{2}$ families were significantly $(P<0.05)$ lower for families that were homozygous for the bnlg1902 marker allele (bin 5.03) from resistant lines 12465 or 12467 than for families that were heterozygous at this marker locus or homozygous for the bnlg1902 marker allele from GG88. Resistance associated with this QTL was expressed only if $\mathrm{F}_{3: 5}$ or $\mathrm{BC}_{2} \mathrm{~S}_{2}$ families were homozygous for marker alleles associated with the resistant inbred parent $\left(\mathrm{P}_{1}\right)$. Marker alleles identified in the $\mathrm{F}_{3: 5}$ mapping population that were in proximity to the resistance QTL on chromosomes 2 and 6 were not polymorphic in crosses of GG88 with 12465 and 12467. Selection for other polymorphic marker loci adjacent to these two regions did not improve Stewart's wilt resistance of $\mathrm{BC}_{2} \mathrm{~S}_{2}$ families.

Additional keywords: Erwinia stewartii, Stewart's bacterial wilt.
Stewart's bacterial wilt of corn (Zea mays), caused by Pantoea stewartii (Syn. Erwinia stewartii (Smith) Dye), is endemic in the United States from the Mid-Atlantic States through the Ohio River Valley to Missouri and Iowa (20). Epidemics of Stewart's wilt also occur sporadically $500 \mathrm{~km}$ north or south of this area $(1,8)$. The bacterium is vectored by the corn flea beetle, Chaetocnema pulicaria Melsh. Stewart's wilt causes relatively minor yield reductions in field corn primarily because most hybrids have levels of resistance that prevent systemic infection (4). Conversely, Stewart's wilt causes considerable damage to certain sweet corn hybrids that are systemically infected during the seedling wilt phase of the disease $(7,16)$. The magnitude of yield reduction in sweet corn is associated with infection at seedling growth stages $(17,22)$, the incidence of systemically infected plants (7), and the level of resistance or susceptibility of the hybrid $(7,13,22)$. Levels of resistance adequate to prevent yield reduction are available in some sweet corn germ plasm $(12,16,18,19)$, but resistance needs to be incorporated into susceptible, early maturing sweet corn germ plasm and into germ plasm derived from susceptible inbreds or hybrids with superior characteristics for processing.

Relatively simply-inherited resistance to Stewart's wilt has been identified in field corn. Wellhausen (25) proposed that two major independent genes, designated $S w 1$ and $S w 2$, and a minor

Corresponding author: J. K. Pataky; E-mail address: j-pataky@uiuc.edu

doi:10.1094/PHYTO-98-4-0469

(C) 2008 The American Phytopathological Society gene, designated $S w 3$, were responsible for Stewart's wilt resistance in the field corn inbred OSF. Seedlings were highly resistant if they contained $S w 1$ and $S w 2$, moderately resistant if they contained only $S w 1$, moderately susceptible if they contained only $S w 2$, and highly susceptible if neither gene was present. Responses were altered slightly by a modifier gene, designated $S w 3$; however, the modifier alone did not significantly improve resistance. One of the major genes in OSF was linked with the $P$-gene for cob and pericarp color on chromosome 1. Smith (21) observed that resistance to the seedling wilt phase of Stewart's disease was conditioned by two independent genes in the field corn inbreds Mo5Rf and C123, but that these genes became complementary in expressing resistance to the leaf blight phase. Following the notation of Wellhausen (25), Smith designated these as $S w 1$ and $S w 2$ although it was not evident that these were the same resistance genes identified by Wellhausen. Smith also proposed that resistance to the seedling wilt phase in the field corn inbreds Oh43, M14, and B14A was conditioned by genes at two additional loci, designated $s w 3$ and $s w 4$. Heterozygosity was required at these loci for expression of resistance in seedlings, or possibly, one of the loci needed to be homozygous recessive (21). Kang (9) proposed that two dominant, duplicate genes conditioned resistance in the field corn inbreds L329 and L765; and that L765 may have additional genes for resistance (modifiers) that caused less severe symptoms in susceptible progeny. Parker and Hooker (15) estimated that one to four factors conditioned Stewart's wilt resistance in the field corn inbreds Pa83, Pa887P, Pa419P, and Pa70. Estimates of broad sense heritability were 46, 80, 85, and $90 \%$, respectively. Blanco et al. (3) concluded that Stewart's wilt resis- 
tance in the field corn inbreds B37, 33-16, and Mo17 was highly heritable and governed predominantly by additive effects conferred by several major genes with the involvement of some modifiers.

A recent review synthesized the results of 50 publications on mapping disease resistance quantitative trait loci (QTL) in corn (26). Only two QTL mapping populations were used to study the inheritance of resistance to Stewart's wilt $(5,14)$. Ming et al. (14) identified a single, dominant gene, designated $S w l$, that conditioned Stewart's wilt resistance in the inbred Ki14. This gene mapped to the short arm of chromosome 1 between the RFLP markers umc167 and umc67 and adjacent to the $P 1$ gene for pericarp color. A region on chromosome 9 that may have been associated with Stewart's wilt resistance also was identified, although Ming et al. (14) were of the opinion that additional studies with larger mapping populations were needed to confirm the role of this QTL. In an $\mathrm{F}_{2: 3}$ mapping population derived from the cross of sweet corn inbreds IL731a by W6786, Brown et al. (5) identified three QTL associated with Stewart's wilt resistance in chromosomal bin locations 4.07, 5.03, and 6.04. The QTL on chromosome 5 was in the general region of the a2 gene which is associated with anthocyanin production. Other QTL were associated with Stewart's wilt reactions in 1 of 2 years, including putative QTL in bins 1.01, 1.04, 1.10, 2.04, 4.01, 6.05, 7.03, and 10.01 .

Because of the limited geographic distribution of $P$. stewartii and its insect vector, marker-assisted selection could enhance the development of Stewart wilt resistant sweet corn inbreds and hybrids. Many sweet corn breeding stations in the continental United States are located where Stewart's disease does not occur on a regular basis (e.g., Idaho, Colorado, Minnesota, Wisconsin, and Florida). Breeders at these locations are reluctant to inoculate with $P$. stewartii in order to avoid an unnecessary introduction of the pathogen. Similarly, many off-season sweet corn breeding nurseries are located in Chile, Hawaii, Australia, or other areas where the pathogen is not present and quarantine restrictions are enforced to prevent its introduction. In these situations when selection for resistance cannot be done phenotypically in field nurseries, marker-assisted selection could be used to avoid generations of backcrossing or selfing without selection.

The objectives of this research were to identify QTL for Stewart's wilt resistance from a mapping population derived from a sweet corn hybrid that is highly resistant to $P$. stewartii and to determine if marker-based selection for those QTL could substantially improve Stewart's wilt resistance in a population derived from a cross of resistant lines and a highly susceptible sweet corn inbred.

\section{MATERIALS AND METHODS}

Identification of QTL associated with Stewart's wilt resistance. A population of $110 \mathrm{~F}_{3: 4}$ families was derived by successive generations of self-pollinating the sweet corn hybrid Bonus. Bonus is a yellow-kernel, sugary-1 hybrid grown for processing. Bonus is as resistant to Stewart's wilt as any commercially available sweet corn hybrid (16). $\mathrm{F}_{3: 5}$ families were developed by selfpollinating a minimum of 10 plants per $\mathrm{F}_{3: 4}$ family and bulking seed within families.

Families were evaluated for reactions to Stewart's wilt in field trials at the University of Illinois Crop Sciences Research and Education Center, Urbana, IL. Trials were planted 9 May 2001 and 24 May 2002. Each trial included three replicates in 2001 and four replicates in 2002 of 110 families plus resistant and susceptible hybrid checks (i.e., Bonus and Jubilee, respectively). The experimental design was a randomized complete block. Each experimental unit included approximately 20 plants in a $3.1 \mathrm{~m}$ single row spaced $76 \mathrm{~cm}$ apart.

Seedlings at the three- to six-leaf stage were inoculated with P. stewartii 12 and 19 June 2001 and 14 and 18 June 2002 using the pinprick method $(2,6)$. The bacterium was originally isolated from naturally infected sweet corn collected in Urbana, IL, in 1995. The pathogen was stored at $-80^{\circ} \mathrm{C}$ in $15 \%$ glycerol and maintained on greenhouse-grown and field-grown plants by alternately inoculating a resistant and a susceptible sweet corn hybrid in order to avoid a loss of virulence $(10,11,24)$. Inoculum was produced by transferring about a dozen $2-\mathrm{cm}$ pieces of surfacesterilized, $P$. stewartii-infected leaf tissue to 1 liter of sterilized nutrient broth in 2-liter Erlenmeyer flasks. Cultures were incubated at room temperature (about $25^{\circ} \mathrm{C}$ ) on shakers for approximately $15 \mathrm{~h}$. Shake cultures were diluted 10 -fold with $0.1 \mathrm{M} \mathrm{NaCl}$ before using as inoculum. Inoculum concentration was not measured.

Stewart's wilt symptoms were rated on 10 July 2001 and 1 July 2002 while plants still had leaf whorls. Each experimental unit was given three ratings to reflect variation among individual plants within a row. The three ratings were averaged for an experimental unit mean. Ratings ranged from 1 to 9 (22): 1 to $4=$ nonsystemic infection with limited, water-soaking, chlorosis and spread of the bacterium; $5=$ limited systemic infection with limited chlorosis, water-soaking, and/or necrosis of noninoculated leaves; 6 to $8=$ severe chlorosis, necrosis, and wilting of 25 to $90 \%$ of the leaf area; and $9=$ dead or nearly dead plants. Plants rated 1 to 3 were considered resistant because infection was not systemic. Plants rated 4 and 5 were considered to have intermediate reactions because infection was limited. Plants rated 6 to 9 were considered susceptible due to severe systemic infection.

Stewart's wilt ratings were analyzed by analysis of variance (ANOVA) and family means were compared by Waller-Duncan Bayesian least significant difference (BLSD) values that approximated $\alpha=0.05$. Estimates of genotypic $\left(\sigma_{\mathrm{g}}^{2}\right)$, error $\left(\sigma_{\mathrm{e}}^{2}\right)$, and genotype by environment $\left(\sigma_{\text {ge }}^{2}\right)$ variances were calculated from the ANOVA and were used to estimate heritability: $h^{2}=\sigma_{\mathrm{g}}^{2} /\left(\sigma_{\mathrm{g}}^{2}+\right.$ $\sigma_{\mathrm{ge}}^{2} / \mathrm{e}+\sigma^{2} / \mathrm{re}$ ). Correlation coefficients for family means were calculated between trials.

The $\mathrm{F}_{3: 4}$ families were fingerprinted at 96 polymorphic simple sequence repeat (SSR) marker loci covering most of the maize genome with an average interval distance of $14.9 \mathrm{cM}$. A linkage map was generated based on a General Mills consensus map. The QTL analysis was conducted using $\mathrm{F}_{3: 5}$ family means across both trials. Composite interval mapping (CIM) was employed for QTL detection and estimation of QTL effects. The linkage map was scanned for the presence of a QTL at $2 \mathrm{cM}$ intervals. A $\log$ likelihood (LOD) threshold of 2.5 was chosen for declaring a putative QTL significant. QTL positions were determined at the LOD maxima in the regions under consideration. Cofactors were selected by stepwise regression. Putative QTL were examined for additive-additive epistatic interactions. The proportion of genotypic variation explained by the respective QTL $\left(\mathrm{Q}^{2}\right)$ was calculated as $R_{\text {adj }}^{2} / h^{2}$. PLABQTL software (23) was used to perform all necessary computations.

Mean phenotypic values calculated from all $\mathrm{F}_{3: 5}$ families were compared (BLSD values approximating $\alpha=0.05$ ) for families homozygous or heterozygous for alleles at individual marker loci associated with Stewart's wilt resistance QTL. Phenotypic means also were compared among all possible combinations of the marker loci associated with the three resistance QTL.

Incorporation of QTL and verification of QTL effect in a susceptible sweet corn inbred. A sweet corn inbred highly susceptible to Stewart's wilt, Green Giant Code 88 (GG88), was crossed with plants from two $F_{3: 4}$ families (12465 and 12467) that were homozygous for marker alleles associated with the Stewart's wilt resistance at three QTL (Fig. 1). GG88 was selected for its extreme susceptibility to Stewart's wilt and because it is not related to the hybrid Bonus from which the two sources of resistance were derived. A population of $422 \mathrm{BC}_{2} \mathrm{~S}_{2}$ families was derived by successive generations of backcrossing to GG88 and self-pollinating. The $\mathrm{BC}_{2}$ generation was derived from $5 \mathrm{BC}_{1}$ 
plants. The $\mathrm{BC}_{2} \mathrm{~S}_{1}$ generation was derived from $12 \mathrm{BC}_{2}$ plants. The $\mathrm{BC}_{2} \mathrm{~S}_{2}$ generation was derived from $35 \mathrm{BC}_{2} \mathrm{~S}_{1}$ plants. Plants were genotyped at each generation during the development of 422 $\mathrm{BC}_{2} \mathrm{~S}_{2}$ families and selected for a group of marker alleles chosen from the 96 marker loci used to fingerprint the $\mathrm{F}_{3: 4}$ families derived from Bonus. Of four SSR marker loci associated with Stewart's wilt resistance from Bonus (described in Results), only the marker allele bnlg1902 (5.03) was polymorphic in crosses with GG88. Hence, the lines derived from crosses of GG88 and 12465 or GG88 and 12467 were genotyped with polymorphic marker loci in chromosome segments adjacent to the QTL associated with Stewart's wilt resistance. Families were genotyped for four marker loci on chromosome 2 [phi083 (bin 2.04), bnlg1909 (bin 2.04), umc1079 (bin 2.06), and bnlg1045 (bin 2.07)], three marker loci on chromosome 5 [bnlg1902 (bin 5.03), bnlg150 (bin5.04), and bnlg2323 (bin5.04)] and one marker locus on chromosome 6 [bnlg1702 (bin 6.05)].

The $422 \mathrm{BC}_{2} \mathrm{~S}_{2}$ families were evaluated phenotypically for reactions to Stewart's wilt in two field trials at the University of Illinois Crop Sciences Research and Education Center, Urbana, IL. Both trials were planted 10 May 2005. One trial included four replicates of $126 \mathrm{BC}_{2} \mathrm{~S}_{2}$ families that were homozygous for marker alleles in each of the three chromosomal segments adjacent to QTL for Stewart's wilt resistance. The second trial included two replicates of $296 \mathrm{BC}_{2} \mathrm{~S}_{2}$ families that had marker alleles from both parents in one or more of the chromosomal segments adjacent to the three resistance QTL. Each trial included a resistant and susceptible check (i.e., Bonus and GG88, respectively) repeated four times within each replicate. The experimental design was a randomized complete block. Each experimental unit included approximately 20 plants in a $3.1 \mathrm{~m}$ single row spaced $76 \mathrm{~cm}$ apart. Plants were inoculated 6 and 13 June 2005 as described previously. Stewart's wilt symptoms were rated from 26 to 29 June while plants still had leaf whorls and again 20 to 21 July after anthesis. Each experimental unit was given 3 ratings from 1 to 9 as described previously. Stewart's wilt ratings were compared among the $\mathrm{BC}_{2} \mathrm{~S}_{2}$ families in each trial using BLSD values that approximated $\alpha=0.05$.

Using all $422 \mathrm{BC}_{2} \mathrm{~S}_{2}$ families, mean Stewart's wilt ratings were calculated for families that were homozygous or heterozygous for

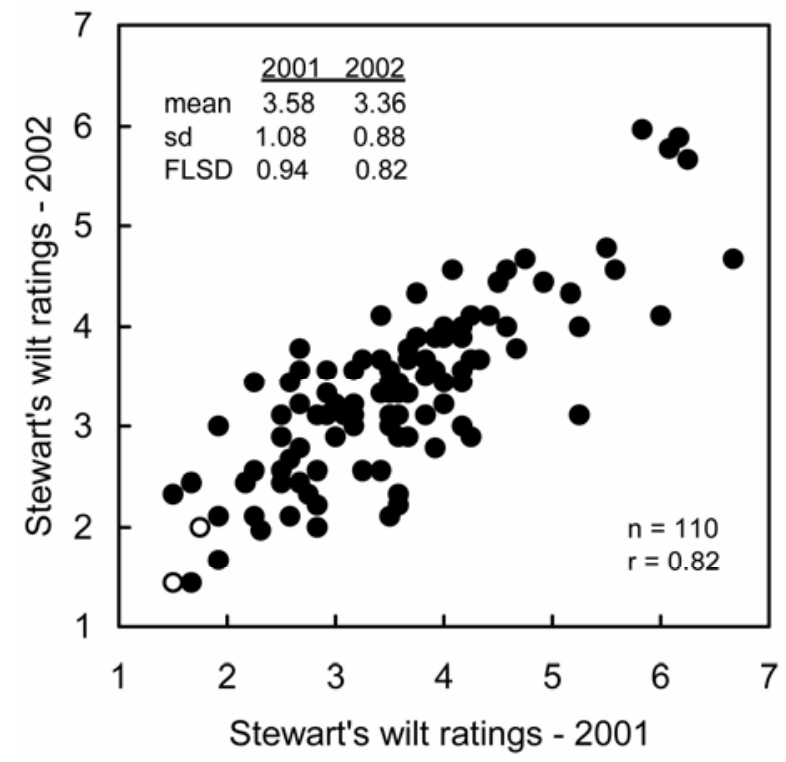

Fig. 1. Stewart's wilt ratings ( 1 to $3=$ resistant, 4 to $5=$ intermediate, 6 to $9=$ susceptible) from inoculated field trials in Urbana, IL, in 2001 and 2002 in which $110 \mathrm{~F}_{3: 5}$ families derived from a Stewart's wilt resistant sweet corn hybrid Bonus were evaluated at vegetative growth stages. Open circles represent the two families, 12465 and 12467, crossed with a susceptible inbred line, Green Giant 88, for marker-based selection studies. alleles at the individual marker locus in closest proximity to each of the three QTL associated with Stewart's wilt resistance, i.e., phi083 (bin 2.04), blng1902 (bin 5.03), and blg1702 (bin 6.05). Mean Stewart's wilt ratings also were compared separately for the $126 \mathrm{BC}_{2} \mathrm{~S}_{2}$ families with chromosomal segments homogeneous for marker alleles associated with the resistant parent (i.e., all marker alleles from the resistant parent in each of the three chromosomal segments) and for the $296 \mathrm{BC}_{2} \mathrm{~S}_{2}$ families with at least one chromosomal segment heterogeneous for marker alleles (i.e., marker alleles from both parents in at least one of three chromosomal segments). Phenotypic means were calculated and compared for all eight possible combinations of chromosomal segments associated with either the resistant or susceptible parent.

\section{RESULTS}

Identification of QTL associated with Stewart's wilt resistance. Mean Stewart's wilt ratings for $\mathrm{F}_{3: 5}$ families derived from Bonus were highly correlated between years, $r=0.82$ (Fig. 1). The genotype by environment term accounted for less than $10 \%$ of the total variation in Stewart's wilt ratings in the combined ANOVA. Therefore, all analyses used mean values of the 2 years. Stewart's wilt ratings differed among families and ranged from 1.4 to 6.1 with a mean of 3.5 (Fig. 2). The resistant and susceptible check hybrids, Bonus and Jubilee, were rated 2.2 and 5.9, respectively. The mean separation value $\left(\mathrm{BLSD}_{\mathrm{k}=100}\right)$ was 0.66 . Heritability of Stewart's wilt ratings was $0.85\left(\sigma_{\mathrm{g}}^{2}=0.669, \sigma_{\mathrm{ge}}^{2}=\right.$ $\left.0.108, \sigma_{\mathrm{e}}^{2}=0.457\right)$.

Three highly significant $(P<0.05)$ QTL for Stewart's wilt resistance were detected on chromosomes 2, 5, and 6 explaining $31 \%$ of the $\sigma_{\mathrm{g}}^{2}$ for Stewart's wilt ratings in a simultaneous fit (Table 1). The marker in the region of chromosome 2 (bin 2.03) that was most closely associated with Stewart's wilt ratings was bnlg2248 (t-value $=-3.49$ ). The marker in the region of chromosome 5 (bin 5.03) that was most closely associated with Stewart's wilt ratings was bnlg1902 (t-value $=-3.54$ ). The markers in the region of chromosome 6 (bin 6.06/6.07) that were most closely associated with Stewart's wilt ratings were umc1296 and bnlg1740 (t-values $=-3.5$ and -3.54 ).

For each of the three resistance QTL, the mean Stewart's wilt ratings for resistant families were 0.6 to 1.0 lower than mean ratings for the susceptible families (Table 2). For the QTL associated with bnlg2248 (bin 2.03) and umc1296 (bin 6.06), mean Stewart's wilt ratings were not significantly different $(P>0.05)$ between families that were homozygous for marker alleles from the resistant parent and families that were heterozygous for

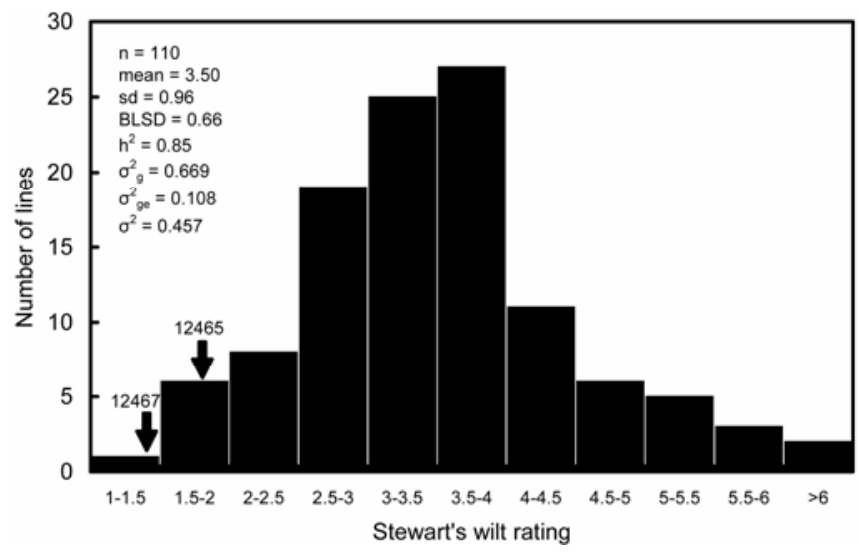

Fig. 2. Distribution of mean Stewart's wilt ratings ( 1 to $3=$ resistant, 4 to $5=$ intermediate, 6 to $9=$ susceptible) from inoculated field trials in Urbana, IL, in 2001 and 2002 in which $110 \mathrm{~F}_{3: 5}$ families derived from a Stewart's wilt resistant sweet corn hybrid Bonus were evaluated at vegetative growth stages. Arrows represent the two families, 12465 and 12467, crossed with a susceptible inbred line, Green Giant 88, for marker-based selection studies. 
marker alleles from both parents (Table 2). For the QTL associated with bnlg1902 (bin 5.03), mean Stewart's wilt ratings were not significantly different $(P>0.05)$ between families that were homozygous for marker alleles from the susceptible parent and families that were heterozygous for marker alleles from both parents (Table 2).

The mean Stewart's wilt rating of $\mathrm{F}_{3: 5}$ families that carried marker alleles associated with the resistant parent at all three QTL was 2.7 , which was significantly $(P<0.05)$ less than the means of 3.8 to 4.2 for families with one or no marker loci associated with the resistant parent (Table 3). Mean Stewart's wilt ratings for families with two marker loci associated with the resistant parent were 3.0, 3.2, and 3.4, which were not significantly different $(P<$ $0.05)$ from the mean for families with three marker loci associated with resistance but were significantly $(P<0.05)$ lower than the mean of 4.2 for families with no marker loci associated with resistance.

Incorporation of QTL into a susceptible sweet corn inbred, GG88. Stewart's wilt ratings differed among the $422 \mathrm{BC}_{2} \mathrm{~S}_{2}$ families derived from crosses of GG88 with 12465 and 12467. Stewart's wilt ratings at the seedling wilt stage (i.e., vegetative growth stages) ranged from 2.0 to 5.5 with a mean of 3.8 . The resistant and susceptible checks, Bonus and GG88, were rated 1.2 and 4.5 , respectively, at the seedling wilt stage. Mean separation values $\left(\mathrm{BLSD}_{\mathrm{k}=100}\right)$ for comparisons of $\mathrm{BC}_{2} \mathrm{~S}_{2}$ families were 0.71 and 0.97 for the trials of 126 homogeneous and 296 heterogeneous families, respectively. Stewart's wilt ratings after anthesis ranged from 1.5 to 9 among all families with a mean of 6.3. The resistant and susceptible checks, Bonus and GG88, were rated 1.1 and 8.9, respectively, after anthesis. Family means were highly correlated between ratings at the seedling wilt stage and after anthesis (i.e., correlation coefficients of 0.81 and 0.79 for the trials of 126 homogeneous and 296 heterogeneous families, respectively). Similarly, analyses of seedling wilt ratings and ratings after anthesis resulted in the same conclusions about incorporation of QTL. Therefore, data are presented only for ratings at the seedling wilt phase which affects sweet corn yield most substantially.

Mean Stewart's wilt ratings of $\mathrm{BC}_{2} \mathrm{~S}_{2}$ families were associated with a marker locus in proximity to the resistance QTL on chromosome 5 (Table 4). The mean Stewart's wilt rating of 3.5 for 192 families that were homozygous for the bnlg1902 marker allele from the resistant parents 12465 or 12467 was significantly $(P<0.05)$ lower than the mean rating of 4.2 for 36 families that were heterozygous and the mean rating of 4.3 for 192 families that were homozygous for the bnlg1902 marker allele from the susceptible parent GG88 (Table 4). Bnlg1902 was the marker on chromosome 5 associated with Stewart's wilt reactions of $\mathrm{F}_{3: 5}$ families derived from Bonus.

Mean Stewart's wilt ratings of $\mathrm{BC}_{2} \mathrm{~S}_{2}$ families were not associated with marker loci in proximity to the resistance QTL on chromosomes 2 and 6 . None of the marker loci most closely associated with putative resistance QTL on chromosomes 2 and 6 in evaluations of $\mathrm{F}_{3: 5}$ families were polymorphic in crosses of GG88 with 12465 and 12467 . Hence, families were genotyped for the markers closest to the putative QTL. Mean Stewart's wilt ratings were not significantly different among $\mathrm{BC}_{2} \mathrm{~S}_{2}$ families that differed for phi083 (bin 2.04) in closest proximity to the putative QTL on chromosome 2 or for bnlg1702 (bin 6.05) in closest proximity to the QTL on chromosome 6 (Table 4).

Similarly, when Stewart's wilt ratings were compared among $\mathrm{BC}_{2} \mathrm{~S}_{2}$ families differentiated by having three, two, one, or no chromosomal segments from resistant parents associated with resistance QTL rather than alleles at a single marker locus proximal to the QTL, results were relatively similar to the analyses based on single marker loci (Table 5, Fig. 3). Mean Stewart's wilt ratings ranged from 2.9 to 3.3 for homogeneous families that had a chromosomal segment from the resistant parent associated with the QTL on chromosome 5. Mean Stewart's wilt ratings ranged from 3.3 to 3.7 for heterogeneous families that had a chromosomal segment from the resistant parent associated with the QTL on chromosome 5 (Table 5). Mean Stewart's wilt ratings ranged from 4.0 to 4.4 for families that had chromosomal segments from the resistant parents associated with QTL on chromosomes 2 and 6 but not on chromosome 5 .

Stewart's wilt was not systemic (ratings below 3) for $25 \%$ of 164 families that contained a segment on chromosome 5 with all alleles from the resistant parents at marker loci bnlg1902, bnlg150, and bnlg2323 (Fig. 3). Stewart's wilt ratings were below 3 for only 2 of 252 families that had an allele from the susceptible parent at these marker loci. Similarly, Stewart's wilt ratings were above 3.9 for $75 \%$ of the families that were not homozygous for marker alleles from the resistant parents at marker loci bnlg1902,

TABLE 2. Mean Stewart's wilt ratings for $\mathrm{F}_{3: 5}$ families derived from Bonus that were homozygous or heterozygous for simple sequence repeat marker alleles associated with reactions to Stewart's wilt

\begin{tabular}{llcc}
\hline \multirow{2}{*}{$\begin{array}{l}\text { Markers, chromosomal location, } \\
\text { and marker genotype }\end{array}$} & $n^{\mathrm{v}}$ & \multicolumn{2}{c}{ Stewart's wilt ratings ${ }^{\mathrm{w}}$} \\
\cline { 3 - 4 } $\begin{array}{l}\text { bn1g2248 (bin 2.03) } \\
\text { P1P1 }\end{array}$ & 28 & $3.1 \mathrm{a}$ & $3.1 \mathrm{a}$ \\
P1P2y & 39 & $3.4 \mathrm{a}$ & $3.2 \mathrm{a}$ \\
P2P2 & 34 & $4.1 \mathrm{~b}$ & $3.7 \mathrm{~b}$ \\
bn1g1902 (bin 5.03) & & & \\
P1P1 & 38 & $3.1 \mathrm{a}$ & $2.9 \mathrm{a}$ \\
P1P2 & 36 & $3.7 \mathrm{~b}$ & $3.5 \mathrm{~b}$ \\
P2P2 & 27 & $3.9 \mathrm{~b}$ & $3.7 \mathrm{~b}$ \\
umc1296 (bin 6.06/6.07) & & & \\
P1P1 & 33 & $3.2 \mathrm{a}$ & $3.0 \mathrm{a}$ \\
P1P2 & 26 & $3.1 \mathrm{a}$ & $3.1 \mathrm{a}$ \\
P2P2 & 42 & $4.1 \mathrm{~b}$ & $3.7 \mathrm{~b}$ \\
\hline
\end{tabular}

${ }^{\mathrm{v}} n$ indicates number of families.

"Stewart's wilt was rated from 1 (resistant) to 9 (dead) (22) at vegetative growth stages in inoculated field trials in Urbana, IL, in 2001 and 2002. Means followed by different letters for comparisons within each marker and year are significantly different $(P=0.05)$ based on Bayesian least significant difference values.

${ }^{x} \mathrm{P} 1 \mathrm{P} 1$, marker alleles homozygous from parent 1.

y P1P2, marker alleles from both parents.

${ }^{\mathrm{z}} \mathrm{P} 2 \mathrm{P} 2$, marker alleles homozygous from parent 2.

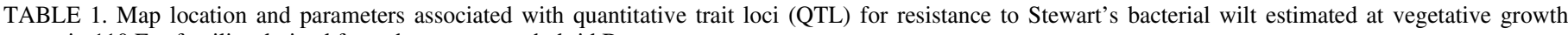
stages in $110 \mathrm{~F}_{2: 4}$ families derived from the sweet corn hybrid Bonus

\begin{tabular}{|c|c|c|c|c|c|c|c|}
\hline $\operatorname{Bin}^{v}$ & QTL position $(\mathrm{cM})^{\mathrm{w}}$ & Marker interval & Support interval & LOD & Additive $^{\mathrm{x}}$ & Dominance & Partial $R^{2 y}$ \\
\hline 2.03 & 50 & bnlg2248-phi083 & $38-62$ & 2.68 & 0.26 & ns & 8.3 \\
\hline 5.03 & 0 & bnlg1902-bnlg 150 & 0-29 & 3.62 & 0.23 & ns & 8.0 \\
\hline \multirow[t]{2}{*}{6.06} & 115 & umc $1296-$ bnlg 1740 & $113-117$ & 3.87 & 0.26 & ns & 9.2 \\
\hline & & & & & & $R^{2}{ }_{\text {adj }}^{\mathrm{z}}=$ & $26.0 \%$ \\
\hline
\end{tabular}

${ }^{v}$ Bin number of flanking marker locus from the Maize Genetic Database (available online).

${ }^{\mathrm{w}}$ QTL postion from the top of the chromosome calculated by PLABQTL.

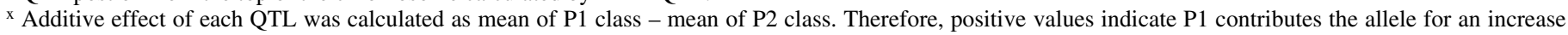
in the trait, and negative values indicate that P2 contributes alleles for an increase in the trait.

y Proportion of the phenotypic variation accounted for by each QTL calculated by multiple regression.

z Proportion of the phenotypic variation explained by the final model. 
bnlg150, and bnlg2323, whereas only $22 \%$ of the 164 families with this chromosomal segment from the resistant parents had ratings above 3.9 (Fig. 3).

\section{DISCUSSION}

Our results are consistent with several aspects of previous studies of the inheritance of resistance to Stewart's bacterial wilt. Based on reactions of $\mathrm{F}_{3: 5}$ families, resistance in the sweet corn hybrid Bonus appears to be highly heritability and associated with at least three QTL that are additive in their effects on Stewart's wilt ratings. Based on mean values of families that were either homozygous or heterozygous for marker alleles associated with the three resistance QTL, two QTL appeared to have dominant or partially dominant gene action while one appeared to be recessive. Previously, resistance to Stewart's wilt in field corn lines was

TABLE 3. Mean Stewart's wilt ratings for $F_{3: 5}$ families derived from Bonus with three, two, one, or no marker loci associated with the resistant parent

\begin{tabular}{lrcc}
\hline \multirow{2}{*}{$\begin{array}{l}\text { Markers loci associated } \\
\text { with resistance }\end{array}$} & $n^{\mathrm{u}}$ & \multicolumn{2}{c}{ Stewart's wilt ratings ${ }^{\mathrm{v}}$} \\
\cline { 2 - 4 } $\mathrm{R}_{2^{-}}{ }^{\mathrm{w}} \mathrm{r}_{5} \mathrm{r}_{5}{ }^{\mathrm{x}} \mathrm{R}_{6^{-}}{ }^{\mathrm{y}}$ & 20 & 2.7 & Range \\
$\mathrm{R}_{2^{-}} \mathrm{r}_{5} \mathrm{r}_{5}$ & 6 & 3.0 & $1.5-3.9$ \\
$\mathrm{R}_{2^{-}} \mathrm{R}_{6^{-}}$ & 25 & 3.2 & $2.0-3.7$ \\
$\mathrm{r}_{5} \mathrm{r}_{5} \mathrm{R}_{6^{-}}$ & 8 & 3.4 & $1.9-4.1$ \\
$\mathrm{R}_{2^{-}}$ & 17 & 3.8 & $2.7-4.0$ \\
$\mathrm{r}_{5} \mathrm{r}_{5}$ & 5 & 3.9 & $2.4-5.2$ \\
$\mathrm{R}_{6^{-}}$ & 7 & 4.2 & $2.6-5.2$ \\
None & 14 & 4.2 & $3.0-6.1$ \\
BLSD & & 0.67 & $3.0-6.1$ \\
Resistant check Bonus & & 2.1 & \\
Susceptible check Jubilee & & 5.9 & \\
\hline
\end{tabular}

u $n$ indicates number of families in each group.

' Stewart's wilt was rated from 1 (resistant) to 9 (dead) (22) at vegetative growth stages in inoculated field trials in Urbana, IL, in 2001 and 2002.

${ }^{\mathrm{w}} \mathrm{R}_{2^{-}}=$families homozygous or heterozygous for bnlg2248 marker alleles (bin 2.03) associated with the resistant parent, P1.

${ }^{\mathrm{x}} \mathrm{r}_{5} \mathrm{r}_{5}=$ families homozygous for bnlg1902 marker alleles (bin 5.03) associated with the resistant parent, P1.

y $\mathrm{R}_{6^{-}}=$families homozygous or heterozygous for umc1296 marker alleles (bin 6.06) associated with the resistant parent, P1.

${ }^{\mathrm{z}} \mathrm{BLSD}_{(0.05)}=$ Bayesian least signficant difference for comparison of phenotypic means with $k=100$.

TABLE 4. Mean Stewart's wilt ratings for $\mathrm{BC}_{2} \mathrm{~S}_{2}$ families derived from crosses of Green Giant 88 with 12465 and 12467 that were homozygous or heterozygous for simple sequence repeat marker alleles in close proximity to putative QTL associated with Stewart's wilt resistance

\begin{tabular}{lrl}
\hline $\begin{array}{l}\text { Markers, chromosmal location, } \\
\text { and marker genotype }\end{array}$ & $n^{\mathrm{v}}$ & Stewart's wilt ratings $^{\mathrm{w}}$ \\
\hline phi083 (bin 2.04) & & \\
P1P1x & 244 & $4.0 \mathrm{a}$ \\
P1P2y & 41 & $3.9 \mathrm{a}$ \\
P2P2 & 132 & $3.8 \mathrm{a}$ \\
bnlg1902 (bin 5.03) & 192 & $3.5 \mathrm{a}$ \\
P1P1 & 36 & $4.2 \mathrm{~b}$ \\
P1P2 & 190 & $4.3 \mathrm{~b}$ \\
P2P2 & & \\
bnlg1702 (bin 6.05) & 202 & $4.0 \mathrm{a}$ \\
P1P1 & 90 & $3.8 \mathrm{a}$ \\
P1P2 & 125 & $3.7 \mathrm{a}$ \\
P2P2 & &
\end{tabular}

${ }^{\mathrm{v}} n$ indicates number of families.

" Stewart's wilt was rated from 1 (resistant) to 9 (dead) (22) at vegetative growth stages in inoculated field trials in Urbana, IL, in 2005. Means followed by different letters for comparisons within each marker and rating are significantly different $(P=0.05)$ based on Bayesian least significant difference values.

${ }^{x}$ P1P1, marker alleles homozygous from 12465 or 12467.

y $\mathrm{P} 1 \mathrm{P} 2$, marker alleles from both parents.

${ }^{\mathrm{z}} \mathrm{P} 2 \mathrm{P} 2$, marker alleles homozygous from inbred GG88. reported to be relatively simply inherited by one or two major dominant genes and a few modifier genes of which some were recessive $(9,21,25)$. Resistance in field corn was highly heritable and genes were additive in their effects on levels of resistance $(21,25)$.

The three QTL identified from Bonus mapped to the same chromosomal region or regions close to those from which QTL were identified previously in sweet corn inbreds. The QTL associated with the marker bnlg1902 mapped about $30 \mathrm{cM}$ distal to the a2 gene on chromosome 5. Brown et al. (5) previously associated a Stewart's wilt resistance QTL from IL731a with the $a 2$ gene.

TABLE 5. Mean Stewart's wilt ratings for $\mathrm{BC}_{2} \mathrm{~S}_{2}$ families derived from crosses of Green Giant 88 with 12465 and 12467 having three, two, one, or no chromosmal segments homogeneous or heterogeneous for marker alleles associated with the resistant parents

\begin{tabular}{|c|c|c|c|c|}
\hline \multirow{2}{*}{$\begin{array}{l}\text { Chromosmal segments } \\
\text { associated with the } \\
\text { resistant parent }\end{array}$} & \multicolumn{2}{|c|}{$\begin{array}{c}\text { Number of } \\
\mathrm{BC}_{2} \mathrm{~S}_{2} \text { families }\end{array}$} & \multicolumn{2}{|c|}{ Stewart's wilt ratings ${ }^{\mathrm{t}}$} \\
\hline & Homo $^{\mathrm{u}}$ & Hetero $^{v}$ & Homo $^{\mathrm{u}}$ & Hetero $^{\mathrm{v}}$ \\
\hline $\mathrm{R}_{2}{ }^{\mathrm{w}} \mathrm{r}_{5}{ }^{\mathrm{x}} \mathrm{R}_{6}{ }^{\mathrm{y}}$ & 12 & 51 & 2.9 & 3.6 \\
\hline $\mathrm{R}_{2} \mathrm{r}_{5}$ & 11 & 31 & 3.3 & 3.5 \\
\hline $\mathrm{R}_{2} \mathrm{R}_{6}$ & 15 & 101 & 4.2 & 4.4 \\
\hline$r_{5} R_{6}$ & 22 & 43 & 3.1 & 3.7 \\
\hline $\mathrm{R}_{2}$ & 11 & 17 & 4.4 & 4.4 \\
\hline $\mathrm{r}_{5}$ & 6 & 16 & 3.3 & 3.3 \\
\hline $\mathrm{R}_{6}$ & 13 & 35 & 4.1 & 4.0 \\
\hline None & 34 & 0 & 4.3 & $\ldots$ \\
\hline $\operatorname{BLSD}_{(0.05)}{ }^{\mathrm{z}}$ & & & $0.27^{\mathrm{z}}$ & 0.27 \\
\hline
\end{tabular}

t Stewart's wilt was rated from 1 (resistant) to 9 (dead) (22) at vegetative growth stages in inoculated field trials in Urbana, IL, in 2005.

" Homogeneous $=$ all marker alleles in the chromosomal segment associated with the resistant parent.

${ }^{\mathrm{v}}$ Heterogeneous $=$ marker alleles in the chromosomal segement from both parents with marker alleles closest to the resistance quantitative trait loci associated with the resistant parent, 12465 or 12467, and other markers associated with the susceptible parent, GG88.

${ }^{\mathrm{w}} \mathrm{R}_{2}=$ families with alleles at marker loci phi083, bnlg1909, umc1079, and bnlg1045 on chromosome 2 associated with the resistant parents, 12465 or 12467.

${ }^{\mathrm{x}} \mathrm{r}_{5}=$ families with alleles at marker loci bnlg1902, bnlg150, and bnlg2323 on chromosome 5 associated with the resistant parents, 12465 or 12467.

${ }^{y} R_{6}=$ families homozygous or heterozygous for bnlg 1702 marker alleles on chromosome 6 associated with the resistant parents, 12465 or 12467.

${ }^{\mathrm{z}} \mathrm{BLSD}_{(0.05)}=$ Bayesian least signficant difference for comparison of phenotypic means with $\alpha=0.05$.

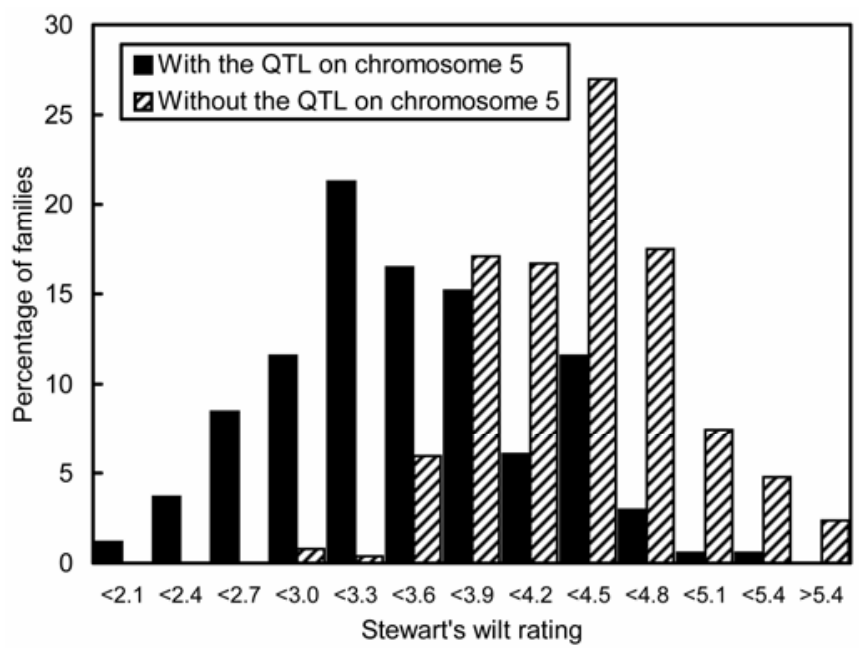

Fig. 3. Distributions of Stewart's wilt ratings at the seedling wilt phase in inoculated field trials in Urbana, IL, in 2005: $164 \mathrm{BC}_{2} \mathrm{~S}_{2}$ families thought to have the Stewart's wilt resistance quantitative trait loci (QTL) on chromosome 5 are homozygous for marker alleles (bnlg1902, bng150, and bnlg2323) from the resistant parents (12465 or 12467) and $252 \mathrm{BC}_{2} \mathrm{~S}_{2}$ families without the resistance QTL are heterozygous for alleles at these marker loci or homozygous for alleles from the susceptible parent Green Giant 88 
The other two QTL from Bonus mapped to regions of chromosomes 2 and 6 in proximity to Stewart's wilt resistance QTL from either IL731a or W6786 (5).

Failure to identify QTL in $\mathrm{F}_{3: 5}$ families derived from Bonus that conveyed larger levels of Stewart's wilt resistance may have been due to an inadequate size of the $F_{3}$ population derived from Bonus, inadequate coverage of the genome with marker loci, or homozygosity in Bonus for major gene resistance. Although at least four marker loci used to fingerprint the $F_{3: 4}$ families (i.e., bnlg1203, umc1397, bnlg1811, and bnlg2295) were in a region of chromosome 1 near the $a l$ and $S w l$ genes, we did not find a major dominant gene on chromosome 1 in the region of the $P 1$ gene as did Wellhausen (25) and Ming et al. (14). Possibly, both or neither inbred parents of Bonus carry the $S w 1$ gene.

The Stewart's wilt resistance QTL on chromosomes 2 and 6 appeared to have dominant or partially dominant gene action in our $F_{3: 5}$ families, which is similar to other major genes for Stewart's wilt resistance $(14,21,25)$. The QTL that we identified on chromosome 5 appeared to be recessive with an effect on phenotypes similar to the recessive modifier gene, $s w 4$, proposed by Smith (21). Additional experiments including tests of allelism are needed to determine if the QTL on chromosome 5 is the same as the recessive modifier gene $s w 4$.

Of the three Stewart's wilt resistance QTL identified from $\mathrm{F}_{3: 5}$ families derived from Bonus, only the QTL on chromosome 5, which was associated with bnlg1902, was identified in the $\mathrm{BC}_{2} \mathrm{~S}_{2}$ families derived from crosses of a susceptible inbred GG88 with two of the most resistant $F_{3: 4}$ families, 12465 and 12467 . Crosses of GG88 with 12465 and 12467 were polymorphic for bnlg1902 and for two other markers, bnlg 150 and bnlg2323, that are linked to bnlg1902. Based on the Maize Genetic and Genomics Database, the chromosomal segment flanked by bnlg1902 and bnlg150 contains the $a 2$ gene which previously was associated with a QTL for Stewart's wilt resistance. Incorporation of this chromosomal segment into GG88 should appreciably improve Stewart's wilt resistance of inbred lines based on our observations of reactions of the $\mathrm{BC}_{2} \mathrm{~S}_{2}$ families (Fig. 3). However, both inbred parents of a hybrid may need this resistance QTL in order to improve hybrid performance.

Crosses of GG88 with 12465 and 12467 were not polymorphic for bnlg2248 and umc1296, the marker loci most closely associated with the putative resistance QTL on chromosomes 2 and 6, respectively. Selection for other marker loci in proximity to these two loci or for a chromosomal segment adjacent to bnlg2248 on chromosome 2 did not improve Stewart's wilt resistance of $\mathrm{BC}_{2} \mathrm{~S}_{2}$ families. Failure to improve Stewart's wilt resistance in $\mathrm{BC}_{2} \mathrm{~S}_{2}$ families by selection for marker loci on chromosomes 2 and 6 could have been due to incorrect identification of these QTL in the $\mathrm{F}_{3: 5}$ families derived from Bonus, due to selection for markers that were not in close enough proximity to the resistance QTL, or the result of similar or the same genes already occurring at those loci in the susceptible parent GG88. Also, selection may have been affected by the relatively small sample size in early generations: $35 \mathrm{BC}_{2} \mathrm{~S}_{1}$ families derived from $12 \mathrm{BC}_{2}$ plants.

\section{LITERATURE CITED}

1. Anderson, T. R., and Buzzell, R. I. 1986. Distribution and severity of Stewart's bacterial wilt of dent corn in Ontario, 1985. Can. Plant Dis. Surv. 66:23-25.
2. Blanco, M. H., Johnson, M. G., Colbert, T. R., and Zuber, M. S. 1977. An inoculation technique for Stewart's wilt disease of corn. Plant Dis. Rep. 61:413-416.

3. Blanco, M. H., Zuber, M. S., Wallin, J. R., Loonan, D. V., and Krause, G. F. 1979. Host resistance to Stewart's disease in maize. Phytopathology 69:849-853.

4. Braun, E. J. 1982. Ultrastructural investigation of resistant and susceptible maize inbreds infected with Erwinia stewartii. Phytopathology 72:159166.

5. Brown, A. F., Juvik, J. A., and Pataky, J. K. 2001. Quantitative trait loci in sweet corn associated with partial resistance to Stewart's wilt, northern corn leaf blight, and common rust. Phytopathology 91:293300 .

6. Chang, C. M., Hooker, A. L., and Lim, S. M. 1977. An inoculation technique for determining Stewart's bacterial blight reaction in corn. Plant Dis. Rep. 61:1077-1079.

7. Freeman, N. D., and Pataky, J. K. 2001. Levels of Stewart's wilt resistance necessary to prevent reductions in yield of sweet corn hybrids. Plant Dis. 85:1278-1284.

8. Kang, M. S. 1987. First report of Stewart's wilt of maize in Louisiana. Plant Dis. 71:281.

9. Kang, M. S. 1990. Inheritance of resistance to Stewart's bacterial wilt in maize. Plant Breed. 104:173-175.

10. Lincoln, R. E. 1939. Host-parasite interactions with bacterial wilt of maize. Science 89:159-160.

11. McNew, G. L. 1940. Factors influencing attenuation of Phytomonas stewartii cultures. J. Bacteriol. 39:171-186.

12. Meyer, A. C., Pataky, J. K., and Juvik, J. A. 1991. Partial resistance to northern leaf blight and Stewart's wilt in sweet corn germ plasm. Plant Dis. 75:1094-1097.

13. Michener, P. M., Freeman, N. D., and Pataky, J. K. 2003. Relationships between reactions of sweet corn hybrids to Stewart's wilt and incidence of systemic infection by Erwinia stewartii. Plant Dis. 87:223-228.

14. Ming, R., Brewbaker, J. L., Moon, H. G., Musket, T. A., Holley, R. N., Pataky, J. K., and McMullen, M. D. 1999. Identification of RFLP markers linked to a major gene, $s w l$, conferring resistance to Stewart's wilt in maize. Maydica 44:319-323.

15. Parker, G. E., and Hooker, A. L. 1993. Inheritance of resistance to Erwinia stewartii in four inbred lines of dent corn: Qualitative and quantitative analyses. Maydica 38:221-229.

16. Pataky, J. K. 2004. Reactions of sweet corn hybrids to prevalent diseases: October 2004. Pages 119-142 in: Midwest Vegetable Variety Trial Report for 2004. Purdue University AES Bull. No. 2004-B17538.

17. Pataky, J. K., du Toit, L. J., Kunkel, T. E., and Schmitt, R. A. 1996. Severe Stewart's wilt in central Illinois on sweet corn hybrids moderately resistant to Erwinia stewartii. Plant Dis. 80:104.

18. Pataky, J. K., du Toit, L. J., and Freeman, N. D. 2000. Stewart's wilt reactions of an international collection of Zea mays germplasm inoculated with Erwinia stewartii. Plant Dis. 84:901-906.

19. Pataky, J. K., du Toit, L. J., Revilla, P., and Tracy, W. F. 1998. Reactions of open-pollinated sweet corn to Stewart's wilt, common rust, northern leaf blight, and southern leaf blight. Plant Dis. 82:939-944.

20. Robert, A. L. 1955. Bacterial wilt and Stewart's leaf blight of corn. USDA Farmer's Bull. No. 2092.

21. Smith, D. R. 1971. Inheritance of reaction to Stewart's disease (bacterial wilt) in dent corn. MS thesis, University of Illinois, Urbana.

22. Suparyono, and Pataky, J. K. 1989. Influence of host resistance and growth stage at the time of inoculation on Stewart's wilt and Goss's wilt development and sweet corn hybrid yield. Plant Dis. 73:339-345.

23. Utz, H. F., and Melchinger, A. E. 1996. PLABQTL: A program for composite interval mapping of QTL. J. Quant. Trait Loci. Published online. Vol. 2, paper 1. Sponsored by the Crop Science Society of America.

24. Wellhausen, E. J. 1937. Effect of the genetic constitution of the host on the virulence of Phytomonas stewartii. Phytopathology 27:1070-1089.

25. Wellhausen, E. J. 1937. Genetics of resistance to bacterial wilt in maize. Iowa Agric. Exp. Stn. Bull. 224:69-114.

26. Wisser, R. J., Balint-Kurti, P. J., and Nelson, R. J. 2006. The genetic architecture of disease resistance in maize: A synthesis of published studies. Phytopathology 96:120-129. 